\title{
ARAŞTIRMA/RESEARCH
}

\section{Benign prostat hiperplazisi ve mesane taş1 birlikteliğinde perkütan ve transüretral sistolitotripsinin karşılaştırılması}

Comparison of percutaneous cystolithothripsy and transurethral cystolithothripsy for bladder stone disease with benign prostatic enlargement

Onur Karsl1 ${ }^{1}$, Volkan İzol ${ }^{2}$

${ }^{1}$ Kocaeli Derince Eğitim ve Araştırma Hastanesi Üroloji Kliniği; Kocaeli, Turkey

${ }^{2}$ Çukurova Üniversitesi Tip Fakültesi, Üroloji Anabilim Dalı, Adana, Turkey

\begin{tabular}{|c|c|}
\hline & \\
\hline $\begin{array}{l}\text { urpose: In this retrospective study we aimed to compare } \\
\text { peration data of the patients with bladder stone and } \\
\text { enign prostatic enlargement who underwent transurethral } \\
\text { ad percutaneous cystolithothripsy with transurethral } \\
\text { rostate resection (TUR-P). } \\
\text { Iaterials and Methods: Between august } 2012 \text { and } \\
\text { ecember } 2015 \text { the patients with benign prostatic } \\
\text { alargement and bladder stone with the size of minimum } \\
\text { cm were included the study. Patinets who were grouped } \\
\text { percutaneous and transurethral cystolithothripsy } \\
\text { nderwent endoscopic or percutaneous cystolithothripsy } \\
\text { or the bladder stone and the operations were completed } \\
\text { ith TUR prostatectomy. The stone size, prostatic } \\
\text { olume, operation and hospitalisation time and } \\
\text { omplications were compared retrospectively. } \\
\text { esults: } 64 \text { patients were included the study. } 30 \text { patients } \\
\text { ere underwent percutaneous cystolithothripsy and } 34 \\
\text { atients were underwent transurethral cystolithothripsy. } \\
\text { he mean stone size were } 3,5 \pm 0,7 \text { cm }(2.2-5.3) \text { at } \\
\text { ercutaneous group and } 3,4 \pm 0,7 \text { cm }(2.4-5.2) \text { at } \\
\text { ansurethral groups. Though the operation time of } \\
\text { ercutaneous group had a significant difference, there was } \\
\text { o significant difference for urethral catheter removal } \\
\text { me, hospital stay and complications. } \\
\text { iscussion: Treatment of BPH with bladder stone, } \\
\text { ercutaneous cystolithothripsy is safe and reduces the } \\
\text { peration time because of removing the bladder stone by } \\
\text { rge fragments and the suprapubic tube helps bladder } \\
\text { aainage during the prostatic resection. }\end{array}$ & 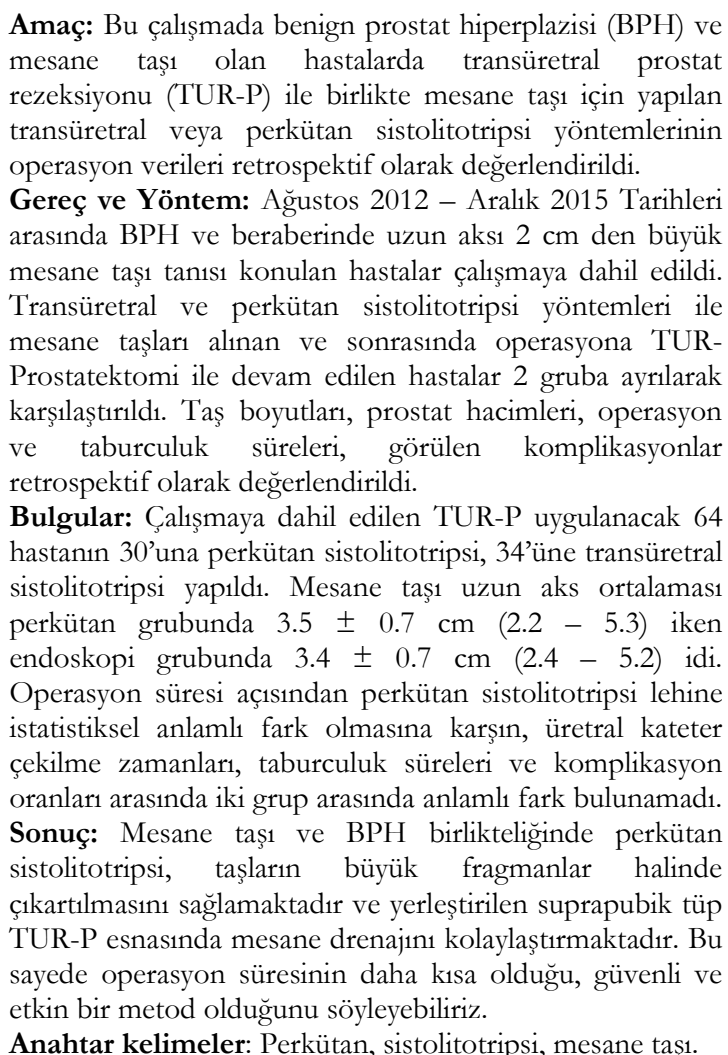 \\
\hline
\end{tabular}
stone. 


\section{GİRİŞ}

Bat1 dünyasında mesane taş1, üriner sistem taşları içinde $\% 5^{\prime}$ lik bir kısmı oluşturmaktadır ${ }^{1}$. Mesane taşları primer ve sekonder mesane taşları olarak iki grupta sınıflandırılırlar. Primer mesane taşları, böbrekten çıkan taşların üreter yoluyla mesaneye ulaşmasıyla oluşurken sekonder mesane taşları, mesane çıkış1 obstrüksiyonları, mesane divertikülü, travma, kateterizasyon, nörojenik mesane, mesanede yabanc1 cisim gibi nedenlerle oluşur ${ }^{2}$. Geleneksel olarak büyük mesane taşları tedavisi için açı operasyon en sik kullanılan yöntemdir ${ }^{3}$. Endoürolojideki modern gelişmelerle birlikte son yillarda mesane taş1 tedavisinde büyük bir değişim yaşanmış, transüretral ve perkütan sistolitotripsi yöntemleri yaygin olarak kullanılmaya başlanmıştır ${ }^{4}$. Transüretral sistolitotripsi, mesane taşları için en sik kullanılan endoürolojik girişim olmasına karşın özellikle büyük mesane taşlarında operasyon süresinin uzamasina ve kalın endoskop kilifi kullanılmasına bağlı olarak üretral kan akımında bozulmaya ve üretral darlık gelişimine yol açabilir ${ }^{5}$. Son yillarda kullanilmakta olan perkütan sistolitotripsi yöntemi ise etkinliğini ve güvenilirliğini kanıtlamış olup özellikle büyük mesane taşlarında üretral hasarın oluşmaması için tercih edilen yöntemler arasına girmiştiro Ayrica operasyon süresinin transüretral sistolitotripsiye göre k1sa olması da bu yöntemin avantajları arasında sayılmaktadır.

$\mathrm{Bu}$ çalışmada benign prostat hiperplazisi (BPH) ve buna bağlı sekonder mesane taşı olan hastalara uygulanan transüretral prostat rezeksiyonu (TUR-P) ile birlikte endoskopik ve perkütan sistolitotripsi yöntemlerinin operasyon verileri retrospektif olarak değerlendirildi.

\section{GEREÇ VE YÖNTEM}

Ağustos 2012 ile Aralık 2015 tarihleri arasında Van Bölge Eğitim ve Araştırma Hastanesi ve Kocaeli Derince Eğitim ve Araştırma Hastanesi Üroloji bölümünde $\mathrm{BPH}$ ve mesane taş1 nedeniyle aynı cerrah tarafindan opere edilen hastaların yine aynı cerrah tarafindan kaydedilen verileri retrospektif olarak tarandi.

Çalışma retrospektif olarak yapıldı ve Helsinki bildirgesine uygun olarak yürütüldü. Hasta verileri kaydedilirken bu verilerin bilimsel amaçla kullanılacağı hastalara anlatıldı ve hastalardan yazılı onam alındı. Çalışmaya dahil edilme kriterleri $2 \mathrm{~cm}$ 'den büyük mesane taşı ve BPH'ya bağlı alt üriner sistem semptomlarının varlığ1 olarak belirlendi ve 64 hastanın verileri çalışmaya dahil edildi.

On yıldan fazla yaşam beklentisi olan ve serum prostat spesifik antijen (PSA) düzeyi yüksek olan hastalarda, transrektal ultrason k1lavuzluğunda 12 kadran prostat biyopsisi ile malignite ekarte edildi. Preoperatif değerlendirmede anamnez, fizik muayene, hemogram, böbrek fonksiyon testleri, idrar kültürü, direk üriner sistem grafisi, üroflovmetri kullanıldı. Prostat boyutları ise transrektal ultrason kullanılarak ölçüldü. İdrar kültüründe üreme olan hastalar uygun antibiyotik tedavisi ald1 ve kontrol kültürlerinde üreme olmayan hastalar operasyona alındi.

\section{Operasyon tekniği}

Operasyonlara $17 \quad \mathrm{~F}$ sistoskop kullanilarak başland. Üretra, prostat, mesane boynu ve mesane içi değerlendirmeler yapıldıktan sonra sistolitotripsiye geçildi. Perkütan sistolitotripsi grubunda sistoskopla direk görüş altında perkütan iğne ile suprapubik bölgeden mesaneye girildi. İğne içerisinden mesaneye kılavuz tel gönderilip, kılavuz tel üzerinden $30 \mathrm{~F}$ amplatz dilatasyon yapildi. Amplatz kilif yerleştirilip $28 \mathrm{~F}$ nefroskop ile mesaneye girildi. Mesanedeki taşlar pnömatik litotripsi ile kırıldı ve fragmanlar forsepsle çıarıldı. $18 \mathrm{~F}$ foley kateter suprapubik olarak yerleştirilip işleme son verildi. Transüretral sistolitotripsi uygulanan hastalarda ise $22 \mathrm{~F}$ sistoskop ile mesaneye girilip pnömatik litotriptör ile mesanedeki taşlar kırıldı. Fragmanlar irrigasyon yardımı ile dışarı alındı. İki grupta da mesane 
taşları alındıktan sonra $24 \mathrm{~F}$ plazmakinetik rezektoskop ile transüretral rezeksiyon işlemi tamamlandi. İki gruptaki hastalara da $22 \mathrm{~F}$ üretral kateter yerleştirilerek operasyonlara son verildi. Operasyon esnasinda transüretral sistolitotripsi grubundaki 1 hastada TUR-P sırasında kapsül perforasyonu gelişti. Perkütan sistolitotripsi grubundaki 1 hastada ise peroperatif kanama gözlendi.

\section{İstatistiksel analiz}

İstatistiksel analizde Mann-Whitney $U$ testi kullanıld1. Gruplar yaş, prostat boyutu, taş boyutu, operasyon süreleri, taburculuk süreleri ve görsel ağrı skalası (VAS) sonuçları açısından karşılaştırıldı. İstatistiksel önem düzeyi $\mathrm{p}=0.05$ olarak alındi.

\section{BULGULAR}

BPH tanısı konulan ve beraberinde mesane taş1 olan 64 hasta çalışmaya dahil edildi. 30 hastaya perkütan sistolitotripsi, 34 hastaya ise transüretral sistolitotripsi ve TUR-P yapild1. Hastaların ortalama yaşı perkütan grubunda $64.6 \pm 5.2$ y1l (56 - 73), transüretral grupta ise $63.6 \pm 5.5$ (55 - 71) y1 idi. Perkütan sistolitotripsi grubunda taş boyutu ortalama 3.5 $\pm 0.7 \mathrm{~cm}(2.2-5.3)$ iken, transüretral sistolitotripsi grubunda ise ortalama $3.4 \pm 0.7$ $\mathrm{cm}(2.4$ - 5.2) idi. Yaş ve taş boyutu açısından gruplar arasinda istatistiksel olarak anlamlı fark yoktu $(\mathrm{p}>0.05)$. Prostat volümleri ise perkütan sistolitotripsi grubunda $69 \pm 9.9 \mathrm{ml}(54-90)$, transüretral sistolitotripsi grubunda $68.3 \pm 10.8$ $\mathrm{ml}(49$ - 90) olarak bulundu.

Ortalama operasyon süreleri perkütan stolitotripsi grubunda $76.8 \pm 9.2$ dakika (64 102), transüretral sistolitotripsi grubunda ise $97.4 \pm 9.7$ (82 - 119) dakika idi. Operasyon süreleri karşılaştırıldığında ise perkütan sistolitotripsi grubu lehine istatistiksel olarak anlamlı bir fark gözlendi $(\mathrm{p}<0.05)$. Perkütan iğne girişinden nefroskopun mesaneye girişine kadar geçen ortalama süre ise $4.7 \pm 1.2$ dakika olarak bulundu. Operasyon süresi perkütan grubunda ortalama $26 \pm 2.9(21-33)$ dakika, transüretral grupta ortalama $41.7 \pm 5.3$ (51 32) dakika idi ve operasyonların ikinci aşaması olan prostatektomi için harcanan süre perkütan grupta $51.8 \pm 8.8$ dakika $(35-61)$, transüretral grupta ise $55.7 \pm 8.9$ dakika $(39-73)$ olarak bulundu $(\mathrm{p}<0.05)$ (Tablo 1$)$.

Perkütan sistolitotripsi grubundaki hastaların postoperatif 1. gün sistostomi kateteri çekildi. Üretral kateter çekilme zamanı ise perkütan sistolitotripsi grubunda ortalama 2.8 gün (2 4), endoskopik sistolitotripsi grubunda ortalama 2.7 gün $(2-6)$ olarak bulundu ve iki grup arasinda istatistiksel anlamlı fark yoktu $(\mathrm{p}>0.05)$. Hastalara postoperatif 1. gün direk üriner sistem grafisi çekilerek taş durumu değerlendirildi ve hiçbir hastada radyolojik olarak rezidü taş gözlenmedi.

Postoperatif komplikasyonlar incelendiğinde ise perkütan sistolitotripsi grubunda bir hastada 2 . gün üretral kateter çekilmesinden sonra suprapubik idrar kaçağı gözlendi ve bu hastaya tekrar üretral kateter koyuldu. Üretral kateter postoperatif 6. günde alınd1. Aynı grupta bir diğer hastada peroperatif başlayan ve postoperatif 2. güne kadar devam eden kanamadan dolay1 hipotansiyon gözlendi. Hastanın hemoglobin değeri $5.6 \mathrm{gr} / \mathrm{dl}$ azaldı ve hastaya 2 ünite eritrosit süspansiyonu verildi. Transüretral sistolitotripsi grubunda ise bir hastada prostatik kapsül perforasyonu oluştu ve üretral kateter 6. Gün alındı. Hastalar postoperatif 0 ve 1 . günde görsel ağrı skalasına göre değerlendirmeye alındı. Perkütan sistolitotripsi grubunda ağr1 skoru ortalamas1 $4.8 \pm 0.5(2-9)$ ve sistolitotripsi grubunda benzer olarak $4.9 \pm 1(2-8)$ idi ve iki grup arasinda istatistiksel anlaml fark yoktu ( $p>0.05)$. Bütün hastalar postoperatif 3. ve 6. ay kontrollerde değerlendirildi ve iki grupta da hiçbir hastada üretral darlık oluşmadığı görüldü. 
Tablo 1. Demografik veriler ve sonuçlar

\begin{tabular}{|c|c|c|c|}
\hline & $\begin{array}{c}\text { Perkütan } \\
\text { Sistolitotripsi }\end{array}$ & $\begin{array}{c}\text { Transüretral } \\
\text { Sistolitotripsi }\end{array}$ & (p) \\
\hline Hasta Savisı (n) & 30 & 34 & \\
\hline Yaş (yll) (ortalama \pm std) & $64.6 \pm 5.2$ & $63.6 \pm 5.5$ & $>0.05$ \\
\hline Taş Boyutu $(\mathrm{cm})$ (ortalama \pm std) & $3.5 \pm 0.7$ & $3.4 \pm 0.7$ & $>0.05$ \\
\hline Prostat Hacmi (ml) (ortalama \pm std) & $69 \pm 9.9$ & $68.3 \pm 10.8$ & $>0.05$ \\
\hline Operasyon Süresi (dk) (ortalama \pm std) & $76.8 \pm 9.2$ & $97.4 \pm 9.7$ & $<0.05$ \\
\hline Sistolitotripsi Süresi (dk)(ortalama \pm std $)$ & $26 \pm 2.9$ & $41.7 \pm 5.3$ & $<0.05$ \\
\hline Prostatektomi Süresi $(\mathrm{dk})($ ortalama \pm std $)$ & $51.8 \pm 8.8$ & $55.7 \pm 8.9$ & $<0.05$ \\
\hline Üretral Katater Çekilme Zamanı (dk) (ortalama \pm std) & 2.8 & 2.7 & $>0.05$ \\
\hline Görsel Ağr1 Skoru (VAS) (ortalama \pm std) & $4.8 \pm 0.5$ & $4.9 \pm 1$ & $>0.05$ \\
\hline
\end{tabular}

\section{TARTIŞMA}

Mesane taşları genellikle sekonder olarak mesane çıkış obstrüksiyonlarına bağlı ve en çok da BPH nedeniyle oluşmaktadır ${ }^{2}$. Endoürolojideki gelişmeler ve yeni teknikler sayesinde, geçmiş yıllarda açı operasyonla alınan mesane taşları, minimal invaziv metodlarla tedavi edilmeye başland $1^{4}$. Deliktaş ve arkadaşlarının yaptığı çalışmada perkütan sistolitotripsi tekniğinin etkinliği ve güvenilirliği belirtilmiştir ${ }^{4}$. Ortalama taş boyutunun 46,25 \pm $9,51 \mathrm{~mm}$ ve ortalama operasyon süresinin 31,25 \pm 8,46 dakika olduğu çalışmada, üretral enstrümantasyon süresinin kısa olması sebebiyle üretral darlık gelişmesinin görülmediği vurgulanmıştır. Bizim çalışmamızda da hiçbir hastada postoperatif üretra darlığı gelişmemiştir.

Singh ve arkadaşlarının yaptığı çalışmada ise üç hasta grubu karşılaştırılmıştır. Birinci grupta transüretral $24 \quad \mathrm{~F}$ nefroskop kullanılmış, perkütan ve transüretral sistolitotripsiye göre operasyon süresinin istatistiksel olarak anlamlı ölçüde k1sa olduğu bulunmuştur ${ }^{7}$. Ancak bu çalışmada üretral giriş-çıkış sayısının diğer iki gruba oranla daha fazla olması ve taşın çıkarılırken üretrada yapacağı olası travma riski göz önüne alındı̆̆ında, transüretral nefroskop kullanımının güvenilirliği sorgulanabilir. Perkütan sistolitotripsi ve transüretral nefroskop kullanılan grupta hastanede kalış süresi benzer bulunmuştur. Çiftçi ve arkadaşlarının yaptığı bir çalışmada ise perkütan sistolitotripsinin özellikle çocuk hastalardaki etkinliği ve güvenilirliği gösterilmiştir ${ }^{8}$. Perkütan sistolitotripsi tekniği ile opere edilen ve üretra çapının küçük olduğu erkek çocuklarda, hastaların postoperatif takiplerinde üretra darlığ1 veya başka bir komplikasyonun gelişmemesi tekniğin güvenilirliği açısından önemli bir bulgudur. Perkütan sistolitotripsi yönteminin üretra darlığ1 riskini azalttığına dair Toktaş ve arkadaşlarının yaptığı çalışmada da bizim çalışmamıza benzer şekilde hastalarının hiç birinde üretra darlığ1 gelişimi görülmemiştir'9. Zhao ve arkadaşlarının yaptığ1 başka bir çalışmada ise büyük mesane taşları ve $\mathrm{BPH}$ birlikteliğinde perkütan sistolitotripsinin güvenli ve minimal invaziv bir metod olduğu gösterilmiştir ${ }^{10}$.

Çalışmamızda, ortalama prostat boyutlarının neredeyse aynı olduğu iki grupta prostatektomi sürelerini karşılaştırdığımızda, perkütan sistolitotripsi yapilan hastalarda TUR-P süresinin anlamlı ölçüde daha kısa olduğu görüldü. $\mathrm{Bu}$ sonuca dayanarak ortaya atabileceğimiz hipotezler ise cerrahın prostatektomiye daha dinç bir fiziksel ve mental durumda devam etmesi ve devamlı suprapubik mesane irrigasyonunun TUR-P sirasinda görsel avantaj sağlaması olarak sayılabilir. Deliktaş ve arkadaşlarının çalışmasında da suprapubik kateterin prostat rezeksiyonunu kolaylaştırdığ1 gösterilmiştir ${ }^{4}$.

Çalışmanın limitasyonları ise verilerin 
retrospektif olarak değerlendirilmesi, hasta sayısının az olması ve zaman içerisinde gelişen öğrenme eğrisinin operasyon sürelerini etkilemesi olarak siralanabilir.

Gelişen teknoloji ile birlikte transüretral veya perkütan girişimler mesane taşı tedavisinde öncelikli tercih edilen yöntemler arasina girmiştir. Teknik alt yapının uygunluğu ve cerrahın deneyimine bağlı olarak hem minimal invaziv yöntemin seçilmesi hem de operasyon süresini ve postoperatif morbiditeyi azaltmak, cerrahın seçimini etkileyen faktörler arasındadır. Mesane taşı ve BPH birlikteliğinde perkütan sistolitotripsi, yüksek etkinlik ve güvenilirliğin yanında sağladığı diğer avantajlarla birlikte öncelikli düşünülmesi gereken yöntemdir.

\section{KAYNAKLAR}

1. Schwartz BF, Stoller ML. The vesical calculus. Urol Clin North Am. 2000;27:333-46.

2. Aron M, Goel R, Gautam G, Seth A, Gupta NP. Percutaneous versus transurethral cystolithotripsy and TUR-P for large prostates and large vesical calculi: refinement of technique and updated data. Int Urol Nephrol. 2007;39:173-7.
3. Maheswari PN, Oswal AT, Bansal M. Percutaneous cystolithotomy for vesical calculi: a better approach. Tech Urol. 1999;5:40-2.

4. Deliktas H, Sahin H, Cullu N, Erdogan O. A modified technique for performing transurethral resection of the prostate combined with percutaneous cystolithotripsy. Urol Int. 2015;95:27680.

5. Tugcu V, Polat H, Ozbay B, Gurbuz N, Eren GA, Tasci AI. Percutaneous versus transurethral cystolithotripsy. J Endourol. 2009;23:237-41.

6. Demirel F, Cakan M, Yalçinkaya F, Demirel AC, Aygün A, Altuğ UU. Percutaneous suprapubic cystolithotripsy approach: for whom? Why? J Endourol. 2006;20:429-31.

7. Singh KJ, Kaur J. Comparison of three different endoscopic techniques in management of bladder calculi. Indian J Urol. 2011;27:10-3.

8. Ciftci H, Gumus K, Demir M, Yilmaz MO, Gulum M, Yeni E et al. Endoscopic cystolithotomy by mini nephroscope: a preliminary study. Minim Invasive Ther Allied Technol. 2015;24:114-8.

9. Toktas G, Sacak V, Erkan E, Kocaaslan R, Demiray $\mathrm{M}$, Unluer $\mathrm{E}$ et al. Novel technique of cytolithotripsy for large bladder stones. Asian J Endosc Surg. 2013;6:245-8.

10. Zhao J, Shi L, Gao Z, Liu Q, Wang K, Zhang P. Minimally invasive surgery for patients with bulky bladder stones and large benign prostatic hyperplasia simultaneously: a novel design. Urol Int. 2013;91:317. 